\title{
Axonal transport and neurological disease
}

James N. Sleigh ${ }^{1,2^{*}}$, Alexander M. Rossor ${ }^{1 *}$, Alexander D. Fellows ${ }^{1}$, Andrew P. Tosolini ${ }^{1}$, Giampietro Schiavo ${ }^{1,2,3 \#}$

${ }^{1}$ Department of Neuromuscular Diseases, UCL Queen Square Institute of Neurology, University College London, London WC1N 3BG, UK.

${ }^{2}$ UK Dementia Research Institute, University College London, London WC1E 6BT, UK.

${ }^{3}$ Discoveries Centre for Regenerative and Precision Medicine, University College London Campus, London WC1N 3BG, UK.

*These authors contributed equally

${ }^{\#}$ Correspondence to:

Giampietro Schiavo giampietro.schiavo@ucl.ac.uk 
Abstract | Axonal transport is the process whereby motor proteins actively navigate microtubules to deliver diverse cargoes, such as organelles, from one end of the axon to the other, and is widely regarded as essential for nerve development, function and survival. Mutations in genes encoding key components of the transport machinery, including motor proteins, motor adaptors and microtubules, have been discovered to cause neurological disease. Moreover, disruptions in axonal cargo trafficking have been extensively reported across a wide range of nervous system disorders. However, whether these impairments have a major causative role in, are contributing to, or are simply a consequence of neuronal degeneration remains unclear. Thus, the fundamental relevance of defective trafficking along axons to nerve dysfunction and pathology is often debated. In this article, we review the latest evidence emerging from human and in vivo studies on whether perturbations in axonal transport are indeed integral to the pathogenesis of neurological disease.

\section{[H1] Introduction}

Intracellular cargo trafficking is tightly and spatiotemporally regulated to maintain cell organisation, homeostasis and survival, and is particularly crucial for nerve cells due to their extreme anatomical and biochemical polarization. Neurons shuttle diverse substances along axon microtubules through a bidirectional, ATP-dependent process known as axonal transport. Anterograde transport, from the cell body to the axon tip, is driven by the kinesin superfamily of motor proteins ${ }^{1}$ and delivers substances such as RNAs, proteins and organelles towards growth cones and synapses ${ }^{2}$. In the opposite direction, retrograde transport is dependent on cytoplasmic dynein ${ }^{3}$ and is essential for processes such as neurotrophic factor signalling ${ }^{4}$, autophagy-lysosomal degradation ${ }^{5,6}$ and the response to nerve injury ${ }^{7}$. Axonal transport thus encompasses a variety of long-distance intracellular trafficking events that require exquisite regulation to preserve neuronal function and viability. The axonal transport machinery, which, 
in addition to motors and microtubules, includes essential motor adaptor proteins, is controlled through intricate protein kinase signalling pathways ${ }^{8,9}$ and post-translational microtubule modifications ${ }^{10,11}$ to ensure efficient transport in neurons.

Given the constant energy demands and distances over which cargoes must be mobilized, it is not surprising to find that mutations in the axonal transport machinery, even in genes that are widely expressed, can cause neurological diseases ${ }^{12-14}$, as can genetic disruption of closely related cellular processes such as endolysosomal sorting ${ }^{15}$, autophagy ${ }^{5}$ and mitochondrial dynamics ${ }^{16}$. In addition, impairments in axonal trafficking have been reported in a multitude of neurological diseases including Alzheimer disease (AD), amyotrophic lateral sclerosis (ALS) and Parkinson disease (PD) ${ }^{17}$, as well as inherited and acquired peripheral neuropathies, such as Charcot-Marie-Tooth disease $(\mathrm{CMT})^{18}$. Furthermore, transport can decline with aging ${ }^{19,20}$, which is a major risk factor in many neurodegenerative conditions, although not all cargoes seem to be equally affected ${ }^{21}$, and the relationship between defective axonal transport and neuronal pathology is often complex. For instance, we do not know why mutations in genes involved in axonal transport can cause such a breadth of neuronal disorders, why neurons with the longest axons are not always preferentially impacted, and why cargospecific deficiencies can occur. Moreover, for those neurological diseases not linked to transport mutations, the question of whether transport defects impair neuronal homeostasis or are simply a consequence of degeneration remains largely unresolved.

To address these questions and illuminate the nuanced mechanisms that regulate axonal trafficking, the main aim of this Review is to examine the evidence for and against a causative role for axonal transport impairments in human nervous system dysfunction. We highlight putative and definite axonal transport-related genes that have been linked to human neurological conditions. We then discuss the relevance of disturbed trafficking in neuronal disorders that are not directly connected to transport machinery, focusing on key findings from 
patient samples and cells, followed by in vivo models of disease. Finally, we consider the merits of targeting axonal transport as a therapeutic strategy for neurodegeneration.

\section{[H1] The axonal transport machinery}

[H2] The microtubule cytoskeleton and motor proteins. Microtubules are crucial for longrange intracellular transport, and are highly dynamic structures consisting of heterodimers of $\alpha$-tubulin and $\beta$-tubulin, isotypes of which are encoded by seven and eight human genes, respectively ${ }^{22}$. Axonal microtubules have a largely uniform morphology that dictates the directionality of motor protein transport: the growing plus-end, which is targeted by the kinesin family of anterograde motors, points towards axon terminals, whereas the stable minus-end faces the cell body and directs cytoplasmic dynein transport ${ }^{23}$. Although the microtubules that are found within axons are more stable than those in dividing cells, a considerable fraction are labile ${ }^{24}$.

The kinesin superfamily of motor proteins is encoded by 45 mammalian genes, 38 of which are expressed in the nervous system, and is classified into 15 subfamilies (kinesin-1 to kinesin-14b) ${ }^{1,25}$. Kinesin-1, kinesin-2 and kinesin-3 seem to be most important for axonal transport ${ }^{12,14}$. Kinesin-1 motors consist of a dimer of kinesin heavy chains, encoded by KIF5A, $K I F 5 B$ and $K I F 5 C$, as well as a dimer of kinesin light chains, encoded by $K L C 1, K L C 2, K L C 3$ and KLC4.

In contrast to the expansive kinesin family, one form of cytoplasmic dynein is essential to retrograde axonal transport. Cytoplasmic dynein is a large ( 1.4 MDa), multi-subunit motor complex consisting of two dynein heavy chains (encoded by DYNC1H1), two intermediate chains (encoded by DYNC1IC1 and DYNC1IC2), two light intermediate chains (encoded by DYNC1LI1 and DYNC1LI2) and three light chain families (Roadblock encoded by DYNLRB1 and DYNLRB2, LC8 encoded by DYNLL1 and DYNLL2, and Tctex encoded by DYNLT1 and 
DYNLT3 $)^{3}$. The core motor is formed from a dynein heavy chain dimer on which the other dynein subunits assemble; the resulting complex binds to microtubules and hydrolyses ATP. Intriguingly, this motor complex by itself lacks major processivity [G] and relies on accessory and adaptor proteins to efficiently transport cargo and carry out its myriad of functions.

[H2] Adaptor proteins. Adaptor proteins bind distinct cargoes and are fundamental to both kinesin and dynein function. Dynactin, a 1.1 MDa complex formed of 23 subunits built around a short, actin-like filament made of actin-related protein 1, is considered to be an essential cofactor for dynein ${ }^{26}$. Dynactin binds dynein and aligns the motors to activate processive movement ${ }^{27}$. Other activating adaptors include BICD2 and Hook proteins ${ }^{3}$. BICD2 is the bestcharacterized member of the mammalian BICD family of proteins (BICD1, BICD2, BICDR1 and BICDR2) and is a potent enhancer of minus-end-directed transport, substantially increasing processivity of the dynein-dynactin complex ${ }^{28-30}$. The BICD family, like other activating adaptors, feature coiled-coil domains [G], which are vital for their interaction with the dynein-dynactin complex ${ }^{26}$.

Two other key dynein regulators are LIS1 and NDEL1. LIS1 binds directly to the motor domain of dynein and, depending on the mode of interaction of LIS1 with the dynein complex, can lead to either increased or decreased microtubule binding ${ }^{31}$. Studies also suggest that this protein can both increase and decrease dynein velocity ${ }^{32,33}$. NDEL1 is a coiled-coil-containing protein that interacts with dynein via its intermediate chain and LC8 subunits, and also interacts with LIS1 ${ }^{3}$. NDEL1 has been shown to tether LIS1 to the dynein complex; however, it is not clear whether NDEL1 inhibits or enhances LIS1 function ${ }^{34,35}$.

Kinesins seem to rely on comparatively few adaptor proteins, perhaps owing to the diversity of kinesin motors compared with the single dynein complex. Most of the kinesin adaptors, including HAP1, JIP1 and TRAK1, are also adaptors for dynein. The shared bi- 
directional adaptors frequently possess overlapping kinesin and dynein interaction regions, suggesting a binary switching mechanism to dictate the directionality of transport, at least in some scenarios ${ }^{36}$.

[H2] Fast and slow axonal transport. For many decades, axonal transport has been subdivided into fast and slow categories on the basis of pulse-chase experiments using radiolabelled amino $\operatorname{acids}^{37}$. Fast axonal transport occurs at a rate of $\sim 50-200 \mathrm{~mm}$ per day and delivers varied cargoes, including vesicles and membrane-bound organelles ${ }^{38}$. Slow axonal transport is crucial for the mobilization of substances such as cytoskeletal proteins (for example, tubulin and actin) and covers distances of $\sim 0.2-10.0 \mathrm{~mm}$ per day ${ }^{38}$. Both fast and slow axonal transport are dependent on the same motor proteins and the distinction in speeds is simply a product of the time that cargoes remain stationary ${ }^{39}$. For a 1 m-long motor neuron, fast axonal transport can convey cargoes between the cell body and the axon tip within a week, whereas slow axonal transport can take longer than a year. However, slow axonal transport is estimated to deliver more than three times as much protein as fast axonal transport, at least in some neuronal subtypes ${ }^{40}$. Although imaging of slow axonal transport is possible, it is technically challenging owing to the time scale over which the process occurs ${ }^{38,41}$; thus, much of what we know about the dynamic properties of cargo trafficking along axons was derived from live-imaging studies of fast axonal transport, beginning in the early $1980 \mathrm{~s}^{42,43}$. Consequently, in this Review, unless otherwise stated, discussions of axonal transport relate to fast axonal transport.

\section{[H1] Mutations in transport machinery genes}

The transport of cargoes along axons requires three basic components: the microtubule network, a kinesin motor or the cytoplasmic dynein-dynactin retrograde complex, and a variety of adaptor proteins. A single cytoplasmic dynein heavy chain is required for retrograde axonal 
transport, whereas more than 40 different kinesins fulfil a variety of roles, including organelle transport, cytoskeletal remodelling and chromosomal dynamics ${ }^{44}$. Missense mutations and small genomic rearrangements in genes encoding these key components of the transport machinery cause a variety of neurological diseases (Table 1, Figure 1). The fact that many of these genes are ubiquitously expressed yet disease-causing mutations result only in a neurological phenotype has been interpreted as evidence that deficits in axonal transport are causative of neurological disease.

Mutations in approximately 20 motor protein-related genes have been reported to cause neuronal disorders, although it is important to state that for many of these genes, no clear role in axonal transport has been demonstrated either in vitro or in vivo. Examining the human phenotype and disease course associated with these mutations, coupled with in vitro and murine disease models, can help us to understand if and how deficits in axonal transport cause neuropathology. At first glance, disease-causing mutations in putative axonal transport-related genes seem to result in a wide range of complex phenotypes, with mutations even in a single gene, such as $D Y N C 1 H 1$, having been linked to a variety of conditions, including cognitive disability, motor dysfunction and epilepsy ${ }^{45}$ However, the reality is more simple, with most disease-causing mutations in the transport machinery giving rise to just a handful of neurodevelopmental disorders (for example, malformations of cortical development (MCDs), congenital fibrosis of extraocular muscles (CFEOM) or spinal muscular atrophy, lower extremity predominant (SMALED)) or neurodegenerative disorders (for example, hereditary spastic paraplegia (HSP), CMT, ALS or parkinsonism). With the exception of mutations in DCTN1, KIF 1A, KIFIC and KIF5A, all other disease-associated axonal transport genes result in a neurodevelopmental, as opposed to a neurodegenerative, phenotype. In the sections that follow, we discuss the neurodevelopmental phenotypes associated with putative axonal 
transport-related gene mutations and how these observations support or refute the hypothesis that deficits in axonal transport contribute to neurological disease.

[H2] Disorders of neuronal migration. MCDs include the conditions lissencephalypachygyria, polymicrogyria and microcephaly, all of which result in severe intellectual disability and are often associated with intractable epilepsy. Although MCDs have a variety of aetiologies, including intrauterine infections and toxin exposure, a genetic cause is being recognized in an increasing number of cases $^{46}$. A clear bias is evident towards genes that encode proteins involved in microtubule-based transport, including kinesins (KIF5C, KIF1A and $K I F 1 C$ ), components of the retrograde transport machinery (DYNC1H1, NDE1 and LISI) and tubulins (TUBA1A, TUBA8, TUBB, TUBB2A, TUBB2B and TUBB3).

Neuronal migration and cerebral cortical development depend on several processes, including interkinetic nuclear migration (INM) and proliferation of radial glial progenitor cells (the precursors of cortical neurons and glia), radial neuronal migration, and terminal translocation. Cytoplasmic dynein, LIS1, NDE1 and KIF1A have all been shown to contribute to INM, which is the oscillatory movement of radial progenitor cell nuclei at the ventricular plate between successive cycles of mitosis ${ }^{47-49}$. Loss-of-function mutations and genomic rearrangements in NDE1 and LIS1 disrupt this process, resulting in MCDs. Following the progression of neuronal progenitor cells from a multipolar to a bipolar orientation, the dyneinLIS1-NDEL1 complex has an essential role in the microtubule-based transport of the nucleus towards the cortical surface ${ }^{50}$. Perturbations of this process are likely to underlie the cortical lamination defects observed in the 'Legs at odd angles' ( $L O a$ ) mice, which are homozygous for a missense mutation in Dynclhl and show normal progenitor cell proliferation but delayed radial somal migration ${ }^{51}$. 
Importantly, although INM and radial neuronal migration are microtubule-based processes, they occur either before or during early stages of neuronal polarization, when the axon is specified from neurite precursors. Therefore, although mutations in axonal transportrelated genes in MCDs reflect the importance of microtubule-based transport in cell division and nuclear migration during cortical development, they do not provide direct evidence that deficits in axonal transport cause MCDs.

[H2] Disorders of axonal pathfinding. CFEOM can occur in the presence of MCD and is characterized by a congenital disorder of eye movement, often accompanied by facial palsy. The fibrosis of the extraocular eye muscles is secondary to a failure of innervation by its corresponding cranial nerve, indicating that CFEOM is a disorder of disrupted axonal guidance. The condition can be caused by missense mutations in the tubulin genes $T U B B 2 B$ and $T U B B 3$, which encode the major $\beta$-tubulin subunits in the CNS and the PNS, or the kinesin gene $K I F 21 A^{52-54}$. The normal function of KIF21A is to reduce the microtubule polymerization rate to prevent microtubule 'catastrophe' (the sudden shrinkage of a microtubule network). CFEOM-causing mutations in $K I F 21 A$ disrupt the autoinhibited state of the protein, leading to a reduction in microtubule polymerization and failure of axonal elongation in the oculomotor nerve. Mutant KIF21A displays enhanced microtubule binding in vitro, but has no effect on microtubule run length $[\mathbf{G}]$ or velocity in vitro, arguing against a role for disrupted axonal transport in $\mathrm{CFEOM}^{55}$. 
[H2] Disorders of motor neuron development. Missense mutations in DYNC1H1 and BICD2, which encode two major components of the retrograde transport complex, cause SMALED, a congenital disorder of motor neuron development predominantly affecting the lower limbs ${ }^{56,57}$. In vitro microtubule gliding assays [G] have shown increased and decreased processive movement, respectively, in the presence of disease-causing mutations in $B I C D 2^{58}$ and $D Y N C 1 H 1^{59}$. Before the discovery of human disease-causing mutations in $D Y N C 1 H 1$, similar missense mutations were reported in three N-ethyl-N-nitrosourea [G] mutant mouse models ${ }^{60,61}$. In the case of the Loa mouse, the mutation was associated with a reduction in retrograde axonal transport speeds both in vitro and in vivo ${ }^{62,63}$.

At first glance, these observations would seem to provide strong evidence in favour of a causal role for defective retrograde axonal transport in human motor neuron diseases, such as ALS. In humans, the SMALED-linked missense mutations in DYNC1H1 and BICD2 cause a developmental disorder of $\alpha$-motor neurons, whereas in mice, similar but not identical mutations cause a developmental loss of $\gamma$-motor and large-diameter 1a sensory neurons. In mice, sensory neuron number is preserved at embryonic day 15 , but dramatic loss of these neurons is observed by postnatal day $1^{60}$, possibly as a result of defective retrograde nerve growth factor signalling ${ }^{63}$. Taken together, these findings suggest that the effects of deficits in retrograde axonal transport are most prominent during early motor and sensory neuron development, and particularly during periods of programmed cell death that are heavily dependent on efficient and timely retrograde neurotrophin signalling. However, in both mice and humans with missense mutations in $\mathrm{DYCN1H1}$, the developmental loss of neurons remains static in adulthood with no evidence of progressive axonal degeneration, indicating that postnatal adult axons are impervious to modest perturbations in retrograde axonal transport, perhaps reflecting the differential demands of developing and mature axons. 
[H2] Mutations in the retrograde transport machinery and neurodegeneration. DCTN1 encodes the $\mathrm{p} 150^{\text {Glued }}$ CAP-Gly subunit of dynactin, which is required for microtubule binding and processive retrograde transport ${ }^{3}$. Polymorphisms are common in this gene; however, missense mutations in four amino acid residues in the second exon cause distal hereditary motor neuropathy type 7 (DHMN7; G59S mutation) or Perry syndrome (G71A/E/R, T72P or Q74P mutations) ${ }^{64-66}$. Although the mutations are only a few amino acids apart, they give rise to vastly different phenotypes. DHMN7 is an autosomal dominant disorder beginning in the fourth to the sixth decade of life, and is characterized by bilateral vocal cord palsies. In addition, patients develop distal motor weakness often affecting the upper limbs that progresses in a slow and stable manner ${ }^{64}$. Perry syndrome, on the other hand, is characterized by parkinsonism, psychiatric symptoms and hypoventilation. No motor neuron degeneration is observed in this condition, and post-mortem studies reveal neuronal loss in the substantia nigra and TAR DNAbinding protein 43 (TDP43) pathology ${ }^{67}$. 
The question of whether these disease-specific mutations impair retrograde axonal transport remains unresolved, with independent studies producing conflicting data. In a Drosophila melanogaster model of DHMN7, axonal transport of green fluorescent proteintagged-Rab7 endosomes [G] was not impaired ${ }^{68}$. This observation was replicated in a mouse model of the disease with evidence of motor nerve degeneration ${ }^{69}$. In a separate study, primary mouse sensory neurons overexpressing the G59S mutant protein showed impaired retrograde lysosomal trafficking - an effect that was not replicated with Perry syndrome mutants ${ }^{70}$. A consistent finding in both studies, however, was the accumulation of $\mathrm{p} 150^{\text {Glued }}$ in distal axons. Moreover, in D. melanogaster motor axons, the G59S mutant led to the accumulation of dense synaptic vesicles and impaired synaptic transmission at the neuromuscular junction ${ }^{68}$. Thus, missense mutations in DCTN1 that cause motor nerve degeneration and nigral neuron degeneration do not seem to result in a general disruption of retrograde transport but might affect the trafficking of specific organelles, such as lysosomes, and might be neuron subtypespecific.

Human mutations in $D Y N C 1 H 1$ were initially linked to $\mathrm{CMT}^{71}$, suggesting that impairments in retrograde axonal transport are involved in peripheral nerve degeneration. However, subsequent clinical descriptions of human $D Y N C 1 H 1$ mutations consistently showed that they cause a developmental and non-progressive loss of motor neurons predominantly affecting the lower limbs, namely, SMALED. In fact, the clinical description of the original published family was of a motor-predominant disorder affecting the lower limbs, in keeping with a diagnosis of SMALED and incorrectly described as CMT. 
[H2] Mutations in the anterograde transport machinery and neurodegeneration. The strongest genetic evidence implicating impaired axonal transport in neurodegeneration came from mutations in the two kinesin genes, $K I F 1 A$ and $K I F 5 A$. Mutations in $K I F 1 A$ give rise to a variety of phenotypes: autosomal recessive loss-of-function mutations cause $\mathrm{HSP}^{72}$, a disease of progressive corticospinal tract degeneration with profound sensory neuropathy, and dominant de novo mutations cause a complex phenotype of MCD, HSP and $\mathrm{CMT}^{73}$. KIF1A is required for INM and neuronal progenitor cell proliferation and migration, and dominantnegative effects on this process are likely to explain the $\mathrm{MCD}^{47}$. In addition, KIF1A transports the neurotrophin receptor TrkA to sensory axon terminals to promote their survival, and loss of KIF1A in mice and humans results in a sensory neuropathy, providing direct evidence that disrupted axonal transport of a specific cargo can lead to axonal degeneration ${ }^{74}$.

Autosomal dominant mutations in KIF5A, clustering in the amino-terminal domain, were first described as a cause of HSP and peripheral neuropathy ${ }^{75}$. In vitro studies using microtubule gliding and cargo transport assays revealed that some, but not all, pathogenic mutations caused a reduction in transport velocities ${ }^{76}$. The effects of these HSP-causing mutations on slow axonal transport of cytoskeletal proteins or the cytoplasmic dynein motor or on axonal transport have not yet been investigated in cellular or in vivo models, partly owing to the limited tools available to image slow axonal transport. Therefore, whether mutations in KIF5A cause peripheral and corticospinal nerve degeneration through deficits in axonal transport remains unclear. Mutations in the carboxy-terminal, cargo-binding domain of KIF5A have recently been linked to a large number of cases of ALS, suggesting that the anterograde delivery of specific cargoes to axon terminals is impaired in this condition 77,78 .

Autosomal dominant mutations in KIF $1 B$ were originally reported to cause CMT type 2 (CMT2) in a single family ${ }^{79}$; however, the lack of confirmation in additional families casts doubt on the pathogenicity of these mutations. 


\section{[H1] Axonal transport and neurodegeneration}

The mutations in transport machinery discussed above provide evidence that alterations in axonal trafficking can impair neuronal homeostasis and lead to neurological disease. It is conceivable, therefore, that disturbances in axonal transport, which have been reported in many, if not most, nervous system disorders ${ }^{17,18}$, could be a major cause of associated neuropathology. However, compromised transport could also be a consequence of neuronal dysfunction and degeneration, and causation has proved difficult to demonstrate in vitro and in vivo. Several reviews have been published that discuss transport deficiencies in neuronal disorders across model systems ${ }^{9,12-18}$. In this section, focusing principally on human and in vivo studies, we will briefly discuss the evidence for and against the idea that transport disruptions contribute to the aetiology of neurological diseases that are not caused by the genetic mutations in transport machinery outlined above.

When axonal transport is perturbed, cargoes are likely to aberrantly accumulate and cause swellings along the axon, as has been shown through genetic disruption of the transport machinery in D. melanogaster and mice ${ }^{80,81}$. This phenomenon has also been observed in disease-relevant neurons in post-mortem studies of patients with diverse neurological conditions. For example, the brains of patients with early-stage AD display swellings in basal forebrain axons before amyloid deposition ${ }^{82}$, motor axons in patients with ALS accumulate phosphorylated neurofilament proteins and organelles in swellings that can selectively ensnare kinesin ${ }^{83,84}$, and axonal accumulations of synaptic vesicles and $\alpha$-synuclein have been observed in hippocampal neurons of patients with $\mathrm{PD}^{85}$. Moreover, a transport deficiency has been indirectly observed in patients with $\mathrm{PD}$, using a method that implements heavy water pulses to assess kinetic biomarkers in cerebrospinal fluid ${ }^{86}$. 
Consistent with these findings, evidence indicates that quantitative and qualitative alterations in the transport machinery, including the microtubule cytoskeleton, are widespread in neurological disorders. For instance, motor protein expression levels are altered in $\mathrm{AD}^{87}$, $\mathrm{ALS}^{88}$, multiple sclerosis $(\mathrm{MS})^{89}$, and $\mathrm{PD}^{90}$ patient samples. Moreover, impairments in microtubule stability and function have been reported in the brains of patients with $\mathrm{AD}^{91,92}$ and induced pluripotent stem cell (iPSC)-derived dopaminergic neurons from patients with $\mathrm{PD}^{93,94}$. These observations have been corroborated by studies in animal and cell models of many neuronal disorders ${ }^{10,95}$, suggesting that impairment and/or deregulation of the cytoskeleton is a frequent pathological feature of neurodegeneration. However, although the findings from human cells and tissues are consistent with the idea that axonal transport disruptions are common in neurological disorders, they neither directly demonstrate transport perturbations nor prove causation.

[H2] iPSC-derived neurons in the study of axonal transport. Many studies are emerging in which individual fluorescently labelled cargoes were tracked while being transported along the axons of human iPSC-derived neurons. Motor neurons generated from CMT2 patients with dominant $M F N 2$ or $N E F L$ mutations displayed reduced mitochondrial transport velocities but no differences in the percentage of motile mitochondria ${ }^{96}$. By contrast, the percentage mitochondrial mobility, but not the velocity, was affected in motor axons derived from patients with spinal muscular atrophy ${ }^{97}$. This change occurred early in the disease course, was linked to swellings, and was specific to the tissue involved in the disease, with no defects being observed in forebrain neurons. These two studies indicate that different aspects of axonal transport are selectively affected by disease, and that analysing a variety of parameters ${ }^{98}$ can potentially provide early mechanistic insight into the initial cause of transport disruption, for example, transport initiation versus maintenance, anterograde versus retrograde trafficking or 
rate versus frequency of transported organelles. The data also suggest that the reported transport disturbances are not likely to be simply due to poor neuronal health, as one would expect that multiple dynamic properties of a variety of cargoes to be altered if this were the case. Additional support for this notion is provided when transport defects are progressive and occur before signs of major cellular upheaval, including neuronal death, as has been reported for mitochondrial deficits in motor neurons derived from ALS patients with FUS mutations ${ }^{99}$.

Mitochondria are the most frequently experimentally tracked axonal cargo, thus, much of what we know about axonal transport comes from this organelle ${ }^{100}$. Mitochondrial transport along axons is typified by frequent pausing, relatively slow speeds and bidirectional movements, in contrast to other cargoes, such as signalling endosomes and autophagosomes, which mainly move in the centripetal direction, and synaptic vesicle precursors and secretory granules, which are powered in the opposite direction. These differences are probably attributable to distinct cargo functions, energy requirements ${ }^{101}$, motors and adaptors ${ }^{12,36}$, and regulatory mechanisms ${ }^{8,9}$. Therefore, a disturbance in one cargo type does not necessarily imply that other cargoes are affected, as has often been documented ${ }^{102,103}$. However, the disruptions could still have a common cause, such as a microtubule deficit that affects the motility of all motors, or the trafficking impairment could reflect a degenerating neuron that is incapable of maintaining homeostasis. Defective axonal transport of additional cargoes has been reported in human iPSC models of disease, for instance, mRNA in TDP43-associated $\mathrm{ALS}^{102}$ and amyloid precursor protein-containing vesicles in $\mathrm{AD}^{104}$. However, multiple cargoes are yet to be routinely analysed in iPSC-derived neurons, as has been done in other systems $^{62,102,105,106}$, and such studies will be paramount if we are to better understand the full contribution of defective axonal transport to neurological disease.

Additional caveats to iPSC experiments include the considerable intrinsic and extrinsic variability that persists in iPSC models, despite continuous improvements ${ }^{107}$. Moreover, we do 
not yet know how robustly a developmentally reprogrammed and re-differentiated cell can model adult-onset neurodegenerative conditions in which the disease-targeted neurons can remain viable for many decades in patients. However, induced neurons directly converted from somatic cells provide a promising alternative to circumvent this issue ${ }^{108}$.

[H2] Studying axonal transport in vivo. In vitro systems and ex vivo tissue preparations do not always accurately replicate the in vivo environment, especially when modelling dynamic, tightly regulated processes such as axonal transport ${ }^{109-112}$, which can be influenced by noncell-autonomous signalling ${ }^{113,114}$ and cell-cell interactions ${ }^{115,116}$. This issue is particularly pertinent for discriminating between cell-autonomous and non-cell-autonomous pathomechanisms, which have been shown to contribute to diverse neuropathologies to varying degrees $^{117}$. Moreover, neuronal activity ${ }^{118,119}$ and maturation ${ }^{105}$ can differentially affect cargo trafficking, as can the location of the cargoes along the axon ${ }^{112,120}$. In vivo transport experiments also have their limitations ${ }^{98}$ and similarly struggle with the pervasive difficulty of distinguishing cause from effect. Nonetheless, bona fide in vivo experiments, though often challenging, are likely to yield more consistent results that accurately reflect the in situ situation. In this section, we concentrate on evidence from in vivo models of neurological disease, in which the trafficking of individual cargoes was directly assessed in live organisms.

Selective expression of fluorescent proteins in distinct organelles has facilitated the assessment of axonal transport in a range of genetic model organisms. The combination of fluorescent reporter strains with an ever-expanding repertoire of disease models has provided considerable evidence that impaired axonal transport can at least contribute to neuronal disease. For instance, intravital imaging in filleted D. melanogaster larvae has been used to model axonal transport impairments in a variety of neurological diseases, including ALS ${ }^{102,103}$, Friedreich ataxia ${ }^{120}$ and $\mathrm{PD}^{121,122}$. In these studies, imaging was predominantly performed on 
motor axons of the segmental nerve, which is perhaps more pertinent to modelling of diseases that affect the motor system, such as ALS, than to non-motor neuron disorders, such as AD. Nonetheless, these findings have been corroborated by similar experiments assessing transport in mechanosensory neurons of Caenorhabditis elegans ${ }^{123,124}$ and motor and dopaminergic axons of zebrafish larvae ${ }^{125,126}$. The latter model has an added advantage over C. elegans and flies of being a vertebrate with myelinated axons. However, one must be wary when interpreting results generated from larval stage, non-mammalian organisms, especially $D$. melanogaster, which lack axonal transport-relevant pathways such as neurotrophin receptor signalling ${ }^{127}$ and require major tissue disruption for imaging, so might not accurately replicate the complex environment of the human nervous system.

Mouse models of human neurological disease also have limitations. Intravital experiments in which axonal transport can be monitored in live, anaesthetized mice currently provide the most accurate setting in which to assess this dynamic process, and have provided some of the most compelling evidence that disturbed transport can contribute to neurological disease by enabling the identification of transport disturbance before symptom onset and cell death.

In vivo deficits in axonal transport of individual cargoes were first reported in the SOD1 ${ }^{\mathrm{G} 93 \mathrm{~A}}$ mouse model of $\mathrm{ALS}^{62}$. Impaired trafficking of neurotrophin-containing signalling endosomes and mitochondria was observed in surgically exposed sciatic nerve axons of presymptomatic mutant mice; retrograde endosome transport speeds were significantly reduced before motor neuron loss and became progressively worse, and mitochondria showed an early increase in pausing in anterograde and retrograde directions without alterations in the proportions of moving mitochondria ${ }^{62}$. In addition, injection of a radiolabelled tracer into the ventral horn of the spinal cord in a SOD $1^{\mathrm{G} 93 \mathrm{~A}}$ mouse strain with a milder disease phenotype revealed pre-symptomatic deficits in slow anterograde transport of cytoskeletal proteins in 
ventral roots ${ }^{128}$; these results were replicated in two additional mutant SOD1 strains (SOD1 ${ }^{\mathrm{G} 37 \mathrm{R}}$ and SOD $\left.1^{\mathrm{G} 85 \mathrm{R}}\right)^{129}$. These data indicate that SOD1-linked ALS is associated with general disruption to the transport machinery that affects multiple cargos and both directions of transport, suggesting an alteration in the microtubule network ${ }^{83,95}$. Progressive, presymptomatic retrograde mitochondrial transport disturbances were independently verified using a second fluorescent reporter strain crossed with SOD1 ${ }^{\mathrm{G} 93 \mathrm{~A}}$ mice, and were replicated in the TDP43 ${ }^{\mathrm{A} 315 \mathrm{~T}}$ mutant transgenic mouse model of $\mathrm{ALS}^{130}$.

Impaired retrograde trafficking of signalling endosomes in live motor axons of the sciatic nerve was also reported in a newly developed TDP43 $3^{\mathrm{M} 337 \mathrm{~V}}$ mouse model of ALS. Unlike the previously discussed ALS mice, this model expresses the mutant transgene at nearendogenous levels, leading to neuromuscular pathology without motor neuron loss ${ }^{131}$. Deficits in signalling endosome dynamics manifested between 1.5 and 3 months and persisted until at least 9 months of age ${ }^{132}$. These results indicate that transport defects can occur in ALS mice without supraphysiological transgene expression, and that axonal transport disturbances, though intricately linked to neuromuscular phenotypes, do not necessarily cause immediate motor neuron death. Moreover, given that the signalling endosome transport deficit is of a similar severity between $\mathrm{SOD} 1^{\mathrm{G} 93 \mathrm{~A}}$ and $\mathrm{TDP} 43^{\mathrm{M} 337 \mathrm{~V}}$ mice, which show major differences in neurodegeneration and survival, additional ALS pathomechanisms are likely to operate in these models ${ }^{133}$.

The data discussed so far suggest that in vivo transport defects are common to all mouse models of ALS. However, a novel humanized FUS mutant mouse, Fus ${ }^{\Delta 14 /+}$, which displays overt and progressive motor neuron loss from 1 year of age ${ }^{134}$, shows no clear impairment in axonal transport of signalling endosomes at 3 and 12 months, and only a minor increase in pausing by 18 months ${ }^{132}$. Similarly, motor neuron degeneration was dissociated from transport disruption in ex vivo intercostal and tibialis nerve preparations from SOD $1^{\mathrm{G} 85 \mathrm{R}}$ mice, which 
did not show disturbances in mitochondrial flux or transport dynamics of cholera toxin B subunit-labelled vesicles ${ }^{135}$. This result does not preclude disruption of transport of other cargoes or in motor axons innervating different muscles. However, these studies suggest that global defects in transport are not common to all ALS mouse models, and that mutations in different genes lead to inherent differences in the pathogenesis of the disease. Moreover, the observation that stark motor neuron loss can occur in the absence of transport disruption in Fus $^{\Delta 14 /+}$ mice indicates that degenerating neurons do not always display defects in axonal trafficking before neuronal death. Perhaps counter to expectation, this idea was supported by in vivo observations from a mouse model of spinal and bulbar muscular atrophy (SBMA), which also shows neuromuscular phenotypes and motor neuron loss yet no disruption in the trafficking of signalling endosomes in sciatic nerve axons ${ }^{136}$.

Taken together, these findings suggest that disrupted axonal transport is not simply a non-specific by-product of neurodegeneration, and that the trafficking defects reported in diverse neurological disease models could have a causative and/or contributory role in the pathology. Indeed, the evidence from the mouse models of ALS indicate that transport disturbances are one of the earliest observable phenotypes. Similarly, acute and chronic mouse models for MS displayed defects in both anterograde and retrograde transport of mitochondria and peroxisomes in normal-appearing spinal cord axons in vivo ${ }^{137}$. These defects resulted in diminished organelle supply to the periphery and preceded the development of morphological abnormalities in axons, cargoes and microtubules ${ }^{137}$, consistent with the idea that impaired axonal transport contributes to secondary axonal loss in MS.

In contrast to the in vivo results obtained in mice, axonal transport defects have been reported in D. melanogaster and iPSC models of mutant FUS-linked ALS ${ }^{102,103}$, and squid axoplasm and ex vivo mouse sciatic nerve models for SBMA ${ }^{138,139}$. These discrepancies between models could reflect distinctions in time points or disease-associated mutations, but 
are probably more likely to be determined by the model system. Therefore, careful consideration must be paid to the experimental model before axonal transport disruption is invoked or disregarded as the cause of neurodegeneration. On balance, the frequency of axonal transport perturbation in disease models suggests that trafficking alterations contribute to neuronal dysfunction in a number of neurological conditions, especially those where broad agreement exists across models, such as mutant TDP43-linked ${ }^{102,103,130,132,140}$ and SOD1-linked $\operatorname{ALS}^{62,127,129,135,141-143}$.

\section{[H1] Axonal transport as a drug target}

If impairments in axonal transport cause or contribute to neurological disease, targeting of deficient cargo trafficking is an attractive therapeutic strategy. Promisingly, in vivo studies in mouse models of disease indicate that such defects can be acutely reversed ${ }^{137,143}$, creating scope to develop and test drugs that modulate transport.

A relatively non-specific approach would be to target neuronal microtubules, the posttranslational modification and dynamics of which are altered, thereby possibly exacerbating transport anomalies, in several neurodegenerative diseases ${ }^{10,11,95}$. Microtubule-stabilizing compounds have shown positive effects in models of various diseases, including AD, ALS and $\mathrm{PD}^{95}$, and also in spinal cord injury ${ }^{144}$, the response to which is dependent on axonal transport $^{7,145}$. However, increased microtubule stabilization produced negative effects in the SOD1 ${ }^{\mathrm{G} 93 \mathrm{~A}}$ mouse model of ALS ${ }^{146}$. Similarly, chemical inhibition of histone deacetylase 6 (HDAC6), which removes acetyl groups from microtubules, thereby diminishing their affinity for motor proteins ${ }^{147}$, has been shown to reverse axonal transport deficits in models of ALS ${ }^{99}$, $\mathrm{HD}^{148}$ and $\mathrm{CMT}^{149,150}$. Consistent with these findings, genetic deletion of Hdac6 can extend SOD1 ${ }^{\mathrm{G} 93 \mathrm{~A}}$ mouse survival and improve motor axon integrity ${ }^{151}$. HDAC6 also affects transport through deacetylation of a protein called MIRO1, which is crucial for the calcium-dependent 
recruitment of motor complexes to mitochondria to facilitate their trafficking ${ }^{152}$; thus, the transport-related effects of HDAC6 inhibition are likely to be multifactorial.

Disease-related impairments in axonal transport are frequently motor protein-specific and/or cargo-specific or affect particular dynamic properties such as percentage mobility, speed or overall flux of cargoes. Therefore, broad modulation of axonal transport might have undesired consequences, such as those associated with the delivery of superfluous cargoes or increases in transport speeds above normal levels, as reported in models of CMT2B ${ }^{153,154}$. This issue is particularly relevant for mitochondria, which, unlike most transported organelles, pause frequently and become anchored at specific points along the axon that require a constant energy supply or calcium buffering ${ }^{100}$. A two-fold increase in the motility of mitochondria, through genetic knockout of the mitochondria-specific docking protein syntaphilin, had no impact on disease progression in $\mathrm{SOD} 1^{\mathrm{G} 93 \mathrm{~A}}$ mice ${ }^{155}$, although the caveat remains that syntaphilin ablation has not been confirmed to modify mitochondrial transport in motor axons or in vivo. Negative stress-related signals can be retrogradely transported along axons ${ }^{114}$ and, if enhanced, might also prove detrimental ${ }^{156}$. Thus, global modification of axonal transport, especially affecting cargoes that are not altered in a disease (either due to cargo specificity or axonal transport being completely unaffected), might not be an ideal treatment strategy for all neurological conditions, and a tailored approach aimed at particular transport mechanisms and organelles could prove more beneficial.

Protein kinases are vital for efficient axonal transport, as they directly phosphorylate many key components of the transport machinery ${ }^{8,9}$. For example, ERK1/2 can phosphorylate dynein intermediate chain to specifically enhance the retrograde transport of signalling endosomes, but not of mitochondria ${ }^{113}$, JNK1-mediated phosphorylation of adaptor protein JIP1 stabilizes the interaction of JIP1 with kinesin, thereby promoting anterograde transport of amyloid precursor protein-containing vesicles over retrograde transport ${ }^{157}$, and CDK5 can 
phosphorylate neurofilaments, thereby inhibiting their slow axonal transport ${ }^{158}$. Disruptions in these and other kinase signalling pathways that are crucial for the maintenance of axonal trafficking have been reported in several neurological conditions ${ }^{8,9}$. For instance, p38 MAPK can negatively regulate axonal transport through phosphorylation of motor and cytoskeletal proteins $^{141,159}$, and its overactivation in the spinal cord in patients and mice with ALS might contribute to the impairments in fast and slow axonal transport that have been reported in this disease $^{141,160-162}$. Inhibition of p38 MAPK can preserve motor neuron integrity and marginally increases $\mathrm{SOD} 1^{\mathrm{G} 93 \mathrm{~A}}$ mouse survival ${ }^{162}$. This strategy was shown to restore signalling endosome transport dynamics in both in vitro primary motor neurons and in vivo sciatic nerve axons of SOD1 ${ }^{\mathrm{G} 93 \mathrm{~A}}$ ALS mice ${ }^{143}$. Although the long-term impact of this treatment could not be assessed owing to the systemic toxicity of the experimental drug, this study provides proof of principle that pharmacological modification of disease-implicated kinases is a promising therapeutic avenue for neurological conditions. However, whether such a strategy can be used to treat transport deficiencies when the targeted kinase is not directly implicated in pathology remains to be seen.

Modification of protein kinases in the nervous system has its challenges ${ }^{163}$, including drug traversal of the blood-brain barrier. In addition, many protein kinases involved in axonal trafficking have multiple transport-related and non-transport-related targets, are involved in diverse processes across cell types, and show considerable crosstalk in downstream signalling cascades $^{164-166}$. Other important considerations are that drugs can differentially influence transport depending on axonal location, at least in cultured neurons ${ }^{106}$, and that retrograde and anterograde transport are not mutually independent; for example, kinesin-1 delivers cytoplasmic dynein to distal axons ${ }^{41}$ and, accordingly, malfunctioning of one motor can impact transport in the opposite direction ${ }^{167,168}$. Therefore, although targeting of axonal transport is in theory a promising therapeutic strategy for neurological disease, the long-term viability and 
impact of such an approach requires considerable investigation. Encouragingly, with a detailed understanding of disease pathways, multiple key nodes of kinase signalling pathways might be modulated to achieve amelioration of neurological disease phenotypes ${ }^{169}$. In the interim, studies in which the ramifications of pharmacological transport correction can be assessed will be invaluable in further determining the importance of axonal transport to neurological diseases. Similarly, kinetic biomarkers, such as those assessed in cerebrospinal fluid of patients with $\mathrm{PD}^{86}$, might provide a method to monitor the disruption of axonal transport in humans while providing a sensitive measure of neuronal dysfunction and the impact of treatment.

\section{[H1] Conclusions}

The delivery of substances to precise subcellular locations is vital to maintaining cell function and viability, and nowhere is this more important than the body's longest and arguably most polarized and energy-demanding cell type, the neuron. Axons can reach well over $1 \mathrm{~m}$ in length in humans and require specialized mechanisms to orchestrate the intricate, bidirectional distribution of multiple cargoes between cell bodies and axon terminals. Therefore, it is not surprising that deficiencies in axonal transport have been invoked as a major causative factor in a range of neurological diseases. However, the evidence is perhaps not as decisive as one might initially expect, not least because of difficulties in deciphering whether early trafficking disturbances cause neuronal dysfunction or whether nerve degeneration leads to transport defects. Although the latter scenario can ultimately contribute to neuropathology and exacerbate the demise of a degenerating neuron, it is not consistent with defective transport playing a central role in disease aetiology and substantially reduces the potential impact of targeting this basic neuronal process for therapeutic intervention. Nevertheless, we have highlighted a number of diseases in which considerable evidence across model systems supports a role for disturbed axonal transport in neuropathology, including some examples 
where defective axonal trafficking is one of the first identifiable phenotypes in the in vivo models. Given the importance of non-cell-autonomous mechanisms to axonal transport regulation, developments in longitudinal intravital imaging should be incorporated into future studies of this process.

As we have discussed, mutations in many genes that encode constituents of axonal transport machinery have been linked to human diseases. Most of these conditions are neurological or display a strong neuronal component, which is indicative of the importance of transport machinery to neuron integrity. Additional mutations in other key transport genes are likely to be identified, but owing to the essential nature of axonal transport, complete loss-offunction mutations in such genes are likely to be embryonic lethal.

A number of therapeutic strategies that augment axonal transport have been tested in disease models and have shown signs of efficacy. The feasibility of gene therapy to combat transport deficiencies has been demonstrated in ALS mice ${ }^{170}$ and is an appealing area for future research, both to help further elucidate transport mechanisms and to highlight potentially viable therapeutic strategies for currently incurable nervous system disorders.

1. Hirokawa, N. \& Tanaka, Y. Kinesin superfamily proteins (KIFs): various functions and their relevance for important phenomena in life and diseases. Exp. Cell Res. 334, 16-25 (2015).

2. Terenzio, M., Schiavo, G. \& Fainzilber, M. Compartmentalized signaling in neurons: from cell biology to neuroscience. Neuron 96, 667-679 (2017).

3. Reck-Peterson, S. L., Redwine, W. B., Vale, R. D. \& Carter, A. P. The cytoplasmic dynein transport machinery and its many cargoes. Nat. Rev. Mol. Cell Biol. 19, 382-398 (2018).

4. Villarroel-Campos, D., Schiavo, G. \& Lazo, O. M. The many disguises of the signalling 
endosome. FEBS Lett. 592, 3615-3632 (2018).

5. Maday, S. Mechanisms of neuronal homeostasis: autophagy in the axon. Brain Res. 1649, $143-150$ (2016).

6. Ferguson, S. M. Axonal transport and maturation of lysosomes. Curr. Opin. Neurobiol. 51, 45-51 (2018).

7. Rishal, I. \& Fainzilber, M. Axon-soma communication in neuronal injury. Nat. Rev. Neurosci. 15, 32-42 (2014).

8. Gibbs, K. L., Greensmith, L. \& Schiavo, G. Regulation of axonal transport by protein kinases. Trends Biochem. Sci. 40, 597-610 (2015).

9. Brady, S. T. \& Morfini, G. A. Regulation of motor proteins, axonal transport deficits and adult-onset neurodegenerative diseases. Neurobiol. Dis. 105, 273-282 (2017).

10. Dubey, J., Ratnakaran, N. \& Koushika, S. P. Neurodegeneration and microtubule dynamics: death by a thousand cuts. Front. Cell. Neurosci. 9, 343 (2015).

11. Barlan, K. \& Gelfand, V. I. Microtubule-based transport and the distribution, tethering, and organization of organelles. Cold Spring Harb. Perspect. Biol. https://doi.org/10.1101/cshperspect.a025817 (2017).

12. Hirokawa, N., Niwa, S. \& Tanaka, Y. Molecular motors in neurons: transport mechanisms and roles in brain function, development, and disease. Neuron 68, 610-638 (2010).

13. Hinckelmann, M.-V., Zala, D. \& Saudou, F. Releasing the brake: restoring fast axonal transport in neurodegenerative disorders. Trends Cell Biol. 23, 634-643 (2013).

14. Maday, S., Twelvetrees, A. E., Moughamian, A. J. \& Holzbaur, E. L. F. Axonal transport: cargo-specific mechanisms of motility and regulation. Neuron 84, 292-309 (2014).

15. Neefjes, J. \& van der Kant, R. Stuck in traffic: an emerging theme in diseases of the nervous system. Trends Neurosci. 37, 66-76 (2014). 
16. DiMauro, S., Schon, E. A., Carelli, V. \& Hirano, M. The clinical maze of mitochondrial neurology. Nat. Rev. Neurol. 9, 429-444 (2013).

17. Millecamps, S. \& Julien, J.-P. Axonal transport deficits and neurodegenerative diseases. Nat. Rev. Neurosci. 14, 161-176 (2013).

18. Prior, R., Van Helleputte, L., Benoy, V. \& Van Den Bosch, L. Defective axonal transport: a common pathological mechanism in inherited and acquired peripheral neuropathies. Neurobiol. Dis. 105, 300-320 (2017).

19. Milde, S., Adalbert, R., Elaman, M. H. \& Coleman, M. P. Axonal transport declines with age in two distinct phases separated by a period of relative stability. Neurobiol. Aging 36, 971-981 (2015).

20. Vagnoni, A., Hoffmann, P. C. \& Bullock, S. L. Reducing Lissencephaly-1 levels augments mitochondrial transport and has a protective effect in adult Drosophila neurons. J. Cell Sci. 129, 178-190 (2016).

21. Sleigh, J.N. \& Schiavo, G. Older but not slower: aging does not alter axonal transport dynamics of signalling endosomes in vivo. Matters https://doi.org/10.19185/matters.201605000018 (2016).

22. Brouhard, G. J. \& Rice, L. M. Microtubule dynamics: an interplay of biochemistry and mechanics. Nat. Rev. Mol. Cell Biol. 19, 451-463 (2018).

23. Rao, A. N. \& Baas, P. W. Polarity sorting of microtubules in the axon. Trends Neurosci. 41, 77-88 (2018).

24. Baas, P. W., Rao, R. N., Matamoros, A. J. \& Leo, L. Stability properties of neuronal microtubules. Cytoskeleton 73, 442-460 (2016).

25. Miki, H., Setou, M., Kaneshiro, K. \& Hirokawa, N. All kinesin superfamily protein, KIF, genes in mouse and human. Proc. Natl Acad. Sci. USA 98, 7004-7011 (2001).

26. Carter, A. P., Diamant, A. G. \& Urnavicius, L. How dynein and dynactin transport 
cargos: a structural perspective. Curr. Opin. Struct. Biol. 37, 62-70 (2016).

27. Zhang, K. et al. Cryo-EM reveals how human cytoplasmic dynein is auto-inhibited and activated. Cell 169, 1303-1314 (2017).

28. McKenney, R. J., Huynh, W., Tanenbaum, M. E., Bhabha, G. \& Vale, R. D. Activation of cytoplasmic dynein motility by dynactin-cargo adapter complexes. Science $\mathbf{3 4 5}, 337-$ $341(2014)$.

29. Schlager, M. A. et al. Bicaudal d family adaptor proteins control the velocity of Dyneinbased movements. Cell Rep. 8, 1248-1256 (2014).

30. Budzinska, M., Wicher, K. B. \& Terenzio, M. Neuronal roles of the bicaudal D family of motor adaptors. Vitam. Horm. 104, 133-152 (2017).

31. DeSantis, M. E. et al. Lis1 has two opposing modes of regulating cytoplasmic dynein. Cell 170, 1197-1208 (2017).

32. Huang, J., Roberts, A. J., Leschziner, A. E. \& Reck-Peterson, S. L. Lis 1 acts as a "clutch" between the ATPase and microtubule-binding domains of the dynein motor. Cell 150, 975-986 (2012).

33. Baumbach, J. et al. Lissencephaly-1 is a context-dependent regulator of the human dynein complex. Elife 6, e21768 (2017).

34. Yi, J. Y. et al. High-resolution imaging reveals indirect coordination of opposite motors and a role for LIS1 in high-load axonal transport. J. Cell Biol. 195, 193-201 (2011).

35. Zyłkiewicz, E. et al. The N-terminal coiled-coil of Ndel1 is a regulated scaffold that recruits LIS1 to dynein. J. Cell Biol. 192, 433-445 (2011).

36. Olenick, M. A. \& Holbaur E. L. F. Dynein activators and adaptors at a glance. J. Cell Sci. 132, jcs227132 (2019).

37. Griffin, J. W., Price, D. L., Drachman, D. B. \& Engel, W. K. Axonal transport to and from the motor nerve ending. Ann. N. Y. Acad. Sci. 274, 31-45 (1976). 
38. Roy, S. Seeing the unseen: the hidden world of slow axonal transport. Neuroscientist 20, $71-81(2014)$.

39. Brown, A., Wang, L. \& Jung, P. Stochastic simulation of neurofilament transport in axons: the "stop-and-go" hypothesis. Mol. Biol. Cell 16, 4243-4255 (2005).

40. Garner, J. A. \& Mahler, H. R. Biogenesis of presynaptic terminal proteins. J. Neurochem. 49, 905-915 (1987).

41. Twelvetrees, A. E. et al. The dynamic localization of cytoplasmic dynein in neurons is driven by kinesin-1. Neuron 90, 1000-1015 (2016).

42. Allen, R. D., Metuzals, J., Tasaki, I., Brady, S. T. \& Gilbert, S. P. Fast axonal transport in squid giant axon. Science 218, 1127-1129 (1982).

43. Brady, S. T., Lasek, R. J. \& Allen, R. D. Fast axonal transport in extruded axoplasm from squid giant axon. Science 218, 1129-1131 (1982).

44. Klinman, E. \& Holzbaur, E. L. F. Walking forward with kinesin. Trends Neurosci. 41, $555-556(2018)$.

45. Schiavo, G., Greensmith, L., Hafezparast, M. \& Fisher, E. M. C. Cytoplasmic dynein heavy chain: the servant of many masters. Trends Neurosci. 36, 641-651 (2013).

46. Poirier, K. et al. Mutations in TUBG1, DYNC1H1, KIF5C and KIF2A cause malformations of cortical development and microcephaly. Nat. Genet. 45, 639-647 (2013).

47. Tsai, J.-W., Lian, W.-N., Kemal, S., Kriegstein, A. R. \& Vallee, R. B. Kinesin 3 and cytoplasmic dynein mediate interkinetic nuclear migration in neural stem cells. Nat. Neurosci. 13, 1463-1471 (2010).

48. Doobin, D. J., Kemal, S., Dantas, T. J. \& Vallee, R. B. Severe NDE1-mediated microcephaly results from neural progenitor cell cycle arrests at multiple specific stages. Nat. Commun. 7, 12551 (2016). 
49. Hu, D. J.-K. et al. Dynein recruitment to nuclear pores activates apical nuclear migration and mitotic entry in brain progenitor cells. Cell 154, 1300-1313 (2013).

50. Tsai, J.-W., Bremner, K. H. \& Vallee, R. B. Dual subcellular roles for LIS1 and dynein in radial neuronal migration in live brain tissue. Nat. Neurosci. 10, 970-979 (2007).

51. Ori-McKenney, K. M. \& Vallee, R. B. Neuronal migration defects in the Loa dynein mutant mouse. Neural Dev. 6, 26 (2011).

52. Poirier, K. et al. Mutations in the neuronal $\beta$-tubulin subunit TUBB3 result in malformation of cortical development and neuronal migration defects. Hum. Mol. Genet. 19, 4462-4473 (2010).

53. Jaglin, X. H. et al. Mutations in the $\beta$-tubulin gene $T U B B 2 B$ result in asymmetrical polymicrogyria. Nat. Genet. 41, 746-752 (2009).

54. Yamada, K. et al. Heterozygous mutations of the kinesin KIF21A in congenital fibrosis of the extraocular muscles type 1 (CFEOM1). Nat. Genet. 35, 318-321 (2003).

55. Cheng, L. et al. Human CFEOM1 mutations attenuate KIF21A autoinhibition and cause oculomotor axon stalling. Neuron 82, 334-349 (2014).

56. Scoto, M. et al. Novel mutations expand the clinical spectrum of DYNC1H1-associated spinal muscular atrophy. Neurology 84, 668-679 (2015).

57. Rossor, A. M. et al. Phenotypic and molecular insights into spinal muscular atrophy due to mutations in BICD2. Brain 138, 293-310 (2015).

58. Huynh, W. \& Vale, R. D. Disease-associated mutations in human BICD2 hyperactivate motility of dynein-dynactin. J. Cell Biol. 216, 3051-3060 (2017).

59. Hoang, H. T., Schlager, M. A., Carter, A. P. \& Bullock, S. L. DYNC1H1 mutations associated with neurological diseases compromise processivity of dynein-dynactin-cargo adaptor complexes. Proc. Natl Acad. Sci. USA 114, E1597-E1606 (2017).

60. Chen, X.-J. et al. Proprioceptive sensory neuropathy in mice with a mutation in the 
cytoplasmic Dynein heavy chain 1 gene. J. Neurosci. 27, 14515-14524 (2007).

61. Hafezparast, M. et al. Mutations in dynein link motor neuron degeneration to defects in retrograde transport. Science 300, 808-812 (2003).

62. Bilsland, L. G. et al. Deficits in axonal transport precede ALS symptoms in vivo. Proc. Natl Acad. Sci. USA 107, 20523-20528 (2010).

63. Zhao, J. et al. Dynclh1 mutation causes proprioceptive sensory neuron loss and impaired retrograde axonal transport of dorsal root ganglion neurons. CNS Neurosci. Ther. 22, 593-601 (2016).

64. Hwang, S. H. et al. Distal hereditary motor neuropathy type 7B with Dynactin 1 mutation. Mol. Med. Rep. 14, 3362-3368 (2016).

65. Farrer, M. J. et al. DCTN1 mutations in Perry syndrome. Nat. Genet. 41, 163-165 (2009).

66. Puls, I. et al. Mutant dynactin in motor neuron disease. Nat. Genet. 33, 455-456 (2003).

67. Mishima, T. et al. Perry syndrome: a distinctive type of TDP-43 proteinopathy. $J$. Neuropathol. Exp. Neurol. 76, 676-682 (2017).

68. Lloyd, T. E. et al. The $\mathrm{p} 150^{\mathrm{Glued}}$ CAP-Gly domain regulates initiation of retrograde transport at synaptic termini. Neuron 74, 344-360 (2012).

69. Chevalier-Larsen, E. S., Wallace, K. E., Pennise, C. R. \& Holzbaur, E. L. F. Lysosomal proliferation and distal degeneration in motor neurons expressing the G59S mutation in the $150^{\text {Glued }}$ subunit of dynactin. Hum. Mol. Genet. 17, 1946-1955 (2008).

70. Moughamian, A. J. \& Holzbaur, E. L. F. Dynactin is required for transport initiation from the distal axon. Neuron 74, 331-343 (2012).

71. Weedon, M. N. et al. Exome sequencing identifies a DYNC1H1 mutation in a large pedigree with dominant axonal Charcot-Marie-Tooth disease. Am. J. Hum. Genet. 89, 308-312 (2011).

72. Rivière, J.-B. et al. KIF1A, an axonal transporter of synaptic vesicles, is mutated in 
hereditary sensory and autonomic neuropathy type 2. Am. J. Hum. Genet. 89, 219-230 (2011).

73. Lee, J.-R. et al. De novo mutations in the motor domain of KIF1A cause cognitive impairment, spastic paraparesis, axonal neuropathy, and cerebellar atrophy. Hum. Mutat. 36, 69-78 (2015).

74. Tanaka, Y. et al. The molecular motor KIF1A transports the TrkA neurotrophin receptor and is essential for sensory neuron survival and function. Neuron 90, 1215-1229 (2016).

75. Reid, E. et al. A kinesin heavy chain (KIF5A) mutation in hereditary spastic paraplegia (SPG10). Am. J. Hum. Genet. 71, 1189-1194 (2002).

76. Füger, P. et al. Spastic paraplegia mutation N256S in the neuronal microtubule motor KIF5A disrupts axonal transport in a Drosophila HSP model. PLoS Genet. 8, e1003066 (2012).

77. Brenner, D. et al. Hot-spot KIF5A mutations cause familial ALS. Brain 141, 688-697 (2018).

78. Nicolas, A. et al. Genome-wide analyses identify KIF5A as a novel ALS gene. Neuron 97, 1268-1283 (2018).

79. Zhao, C. et al. Charcot-Marie-Tooth disease type 2A caused by mutation in a microtubule motor KIF1B $\beta$. Cell 105, 587-597 (2001).

80. Martin, M. et al. Cytoplasmic dynein, the dynactin complex, and kinesin are interdependent and essential for fast axonal transport. Mol. Biol. Cell 10, 3717-3728 (1999).

81. LaMonte, B. H. et al. Disruption of dynein/dynactin inhibits axonal transport in motor neurons causing late-onset progressive degeneration. Neuron 34, 715-727 (2002).

82. Stokin, G. B. et al. Axonopathy and transport deficits early in the pathogenesis of Alzheimer's disease. Science 307, 1282-1288 (2005). 
83. De Vos, K. J. \& Hafezparast, M. Neurobiology of axonal transport defects in motor neuron diseases: opportunities for translational research? Neurobiol. Dis. 105, 283-299 (2017).

84. Toyoshima, I. et al. Kinesin and cytoplasmic dynein in spinal spheroids with motor neuron disease. J. Neurol. Sci. 159, 38-44 (1998).

85. Galvin, J. E., Uryu, K., Lee, V. M. \& Trojanowski, J. Q. Axon pathology in Parkinson's disease and Lewy body dementia hippocampus contains $\alpha$-, $\beta$-, and $\gamma$-synuclein. Proc. Natl Acad. Sci. USA 96, 13450-13455 (1999).

86. Fanara, P. et al. Cerebrospinal fluid-based kinetic biomarkers of axonal transport in monitoring neurodegeneration. J. Clin. Invest. 122, 3159-3169 (2012).

87. Hares, K. et al. Overexpression of kinesin superfamily motor proteins in alzheimer's disease. J. Alzheimers Dis. 60, 1511-1524 (2017).

88. Pantelidou, M. et al. Differential expression of molecular motors in the motor cortex of sporadic ALS. Neurobiol. Dis. 26, 577-589 (2007).

89. Hares, K. et al. Axonal motor protein KIF5A and associated cargo deficits in multiple sclerosis lesional and normal-appearing white matter. Neuropathol. Appl. Neurobiol. 43, $227-241$ (2017).

90. Chu, Y. et al. Alterations in axonal transport motor proteins in sporadic and experimental Parkinson's disease. Brain 135, 2058-2073 (2012).

91. Cash, A. D. et al. Microtubule reduction in Alzheimer's disease and aging is independent of tau filament formation. Am. J. Pathol. 162, 1623-1627 (2003).

92. Zhang, F. et al. Posttranslational modifications of $\alpha$-tubulin in Alzheimer disease. Transl. Neurodegener. 4, 9 (2015).

93. Ren, Y. et al. Parkin mutations reduce the complexity of neuronal processes in iPSCderived human neurons. Stem Cells 33, 68-78 (2015). 
94. Cartelli, D. et al. Parkin absence accelerates microtubule aging in dopaminergic neurons. Neurobiol. Aging 61, 66-74 (2018).

95. Brunden, K. R., Lee, V. M.-Y., Smith, A. B., Trojanowski, J. Q. \& Ballatore, C. Altered microtubule dynamics in neurodegenerative disease: therapeutic potential of microtubule-stabilizing drugs. Neurobiol. Dis. 105, 328-335 (2017).

96. Saporta, M. A. et al. Axonal Charcot-Marie-Tooth disease patient-derived motor neurons demonstrate disease-specific phenotypes including abnormal electrophysiological properties. Exp. Neurol. 263, 190-199 (2015).

97. Xu, C.-C., Denton, K. R., Wang, Z.-B., Zhang, X. \& Li, X.-J. Abnormal mitochondrial transport and morphology as early pathological changes in human models of spinal muscular atrophy. Dis. Model. Mech. 9, 39-49 (2016).

98. Sleigh, J. N., Vagnoni, A., Twelvetrees, A. E. \& Schiavo, G. Methodological advances in imaging intravital axonal transport. F1000Res. 6, 200 (2017).

99. Guo, W. et al. HDAC6 inhibition reverses axonal transport defects in motor neurons derived from FUS-ALS patients. Nat. Commun. 8, 861 (2017).

100. Plucińska, G. \& Misgeld, T. Imaging of neuronal mitochondria in situ. Curr. Opin. Neurobiol. 39, 152-163 (2016).

101. Hinckelmann, M.-V. et al. Self-propelling vesicles define glycolysis as the minimal energy machinery for neuronal transport. Nat. Commun. 7, 13233 (2016).

102. Alami, N. H. et al. Axonal transport of TDP-43 mRNA granules is impaired by ALScausing mutations. Neuron 81, 536-543 (2014).

103. Baldwin, K. R., Godena, V. K., Hewitt, V. L. \& Whitworth, A. J. Axonal transport defects are a common phenotype in Drosophila models of ALS. Hum. Mol. Genet. 25, 2378-2392 (2016).

104. Lacovich, V. et al. Tau isoforms imbalance impairs the axonal transport of the amyloid 
precursor protein in human neurons. J. Neurosci. 37, 58-69 (2017).

105. Moutaux, E. et al. Neuronal network maturation differently affects secretory vesicles and mitochondria transport in axons. Sci. Rep. 8, 13429 (2018).

106. Pal, A. et al. High content organelle trafficking enables disease state profiling as powerful tool for disease modelling. Sci. Data 5, 180241 (2018).

107. Berry, B. J., Smith, A. S. T., Young, J. E. \& Mack, D. L. Advances and current challenges associated with the use of human induced pluripotent stem cells in modeling neurodegenerative disease. Cells Tissues Organs 205, 331-349 (2018).

108. Drouin-Ouellet, J., Pircs, K., Barker, R. A., Jakobsson, J. \& Parmar, M. Direct neuronal reprogramming for disease modeling studies using patient-derived neurons: what have we learned? Front. Neurosci. 11, 530 (2017).

109. Gibbs, K. L., Kalmar, B., Sleigh, J. N., Greensmith, L. \& Schiavo, G. In vivo imaging of axonal transport in murine motor and sensory neurons. J. Neurosci. Methods 257, 26-33 (2016).

110. Lewis, T. L., Turi, G. F., Kwon, S.-K., Losonczy, A. \& Polleux, F. Progressive decrease of mitochondrial motility during maturation of cortical axons in vitro and in vivo. Curr. Biol. 26, 2602-2608 (2016).

111. Smit-Rigter, L. et al. Mitochondrial dynamics in visual cortex are limited in vivo and not affected by axonal structural plasticity. Curr. Biol. 26, 2609-2616 (2016).

112. Knabbe, J., Nassal, J. P., Verhage, M. \& Kuner, T. Secretory vesicle trafficking in awake and anaesthetized mice: differential speeds in axons versus synapses. J. Physiol. 596, 3759-3773 (2018).

113. Mitchell, D. J. et al. Trk activation of the ERK1/2 kinase pathway stimulates intermediate chain phosphorylation and recruits cytoplasmic dynein to signaling endosomes for retrograde axonal transport. $J$. Neurosci. 32, 15495-15510 (2012). 
114. Pathak, A. et al. Retrograde degenerative signaling mediated by the p75 neurotrophin receptor requires $\mathrm{p} 150^{\text {Glued }}$ deacetylation by axonal HDAC1. Dev. Cell 46, 376-387. (2018).

115. Kiryu-Seo, S., Ohno, N., Kidd, G. J., Komuro, H. \& Trapp, B. D. Demyelination increases axonal stationary mitochondrial size and the speed of axonal mitochondrial transport. J. Neurosci. 30, 6658-6666 (2010).

116. Badal, K. K. et al. Synapse formation activates a transcriptional program for persistent enhancement in the bi-directional transport of mitochondria. Cell Rep. 26, 507-517 (2019).

117. Smith, S. E. \& Bonni, A. in The Molecular and Cellular Basis of Neurodegenerative Diseases (ed. Wolfe, M. S.) 415-440 (Elsevier, Amsterdam, 2018).

118. Sajic, M. et al. Impulse conduction increases mitochondrial transport in adult mammalian peripheral nerves in vivo. PLoS Biol. 11, e1001754 (2013).

119. Wang, T. et al. Flux of signalling endosomes undergoing axonal retrograde transport is encoded by presynaptic activity and TrkB. Nat. Commun. 7, 12976 (2016).

120. Shidara, Y. \& Hollenbeck, P. J. Defects in mitochondrial axonal transport and membrane potential without increased reactive oxygen species production in a Drosophila model of Friedreich ataxia. J. Neurosci. 30, 11369-11378 (2010).

121. Devireddy, S., Liu, A., Lampe, T. \& Hollenbeck, P. J. The organization of mitochondrial quality control and life cycle in the nervous system in vivo in the absence of PINK1. J. Neurosci. 35, 9391-9401 (2015).

122. Godena, V. K. et al. Increasing microtubule acetylation rescues axonal transport and locomotor deficits caused by LRRK2 Roc-COR domain mutations. Nat. Commun. 5, 5245 (2014).

123. Fatouros, C. et al. Inhibition of tau aggregation in a novel Caenorhabditis elegans model 
of tauopathy mitigates proteotoxicity. Hum. Mol. Genet. 21, 3587-3603 (2012).

124. Butler, V. J. et al. Tau/MAPT disease-associated variant A152T alters tau function and toxicity via impaired retrograde axonal transport. Hum. Mol. Genet. 28, 1498-1514 (2019).

125. Bergamin, G., Cieri, D., Vazza, G., Argenton, F. \& Mostacciuolo, M. L. Zebrafish $\operatorname{Tg}(\mathrm{hb} 9: M T S-K a e d e)$ : a new in vivo tool for studying the axonal movement of mitochondria. Biochim. Biophys. Acta 1860, 1247-1255 (2016).

126. Dukes, A. A. et al. Live imaging of mitochondrial dynamics in CNS dopaminergic neurons in vivo demonstrates early reversal of mitochondrial transport following $\mathrm{MPP}^{+}$exposure. Neurobiol. Dis. 95, 238-249 (2016).

127. Bothwell, M. Recent advances in understanding neurotrophin signaling. F1000Res. 5, 1885 (2016).

128. Zhang, B., Tu, P., Abtahian, F., Trojanowski, J. Q. \& Lee, V. M. Neurofilaments and orthograde transport are reduced in ventral root axons of transgenic mice that express human SOD1 with a G93A mutation. J. Cell Biol. 139, 1307-1315 (1997).

129. Williamson, T. L. \& Cleveland, D. W. Slowing of axonal transport is a very early event in the toxicity of ALS-linked SOD1 mutants to motor neurons. Nat. Neurosci. 2, 50-56 (1999).

130. Magrané, J., Cortez, C., Gan, W.-B. \& Manfredi, G. Abnormal mitochondrial transport and morphology are common pathological denominators in SOD1 and TDP43 ALS mouse models. Hum. Mol. Genet. 23, 1413-1424 (2014).

131. Gordon, D. et al. Single-copy expression of an amyotrophic lateral sclerosis-linked TDP43 mutation $(\mathrm{M} 337 \mathrm{~V})$ in BAC transgenic mice leads to altered stress granule dynamics and progressive motor dysfunction. Neurobiol. Dis. 121, 148-162 (2019).

132. Sleigh, J. N. et al. ALS mice carrying pathological mutant TDP-43, but not mutant FUS, 
display axonal transport defects in vivo. BioRxiv https://doi.org/10.1101/438812 (2018).

133. Hardiman, O. et al. Amyotrophic lateral sclerosis. Nat. Rev. Dis. Primers 3, 17071 (2017).

134. Devoy, A. et al. Humanized mutant FUS drives progressive motor neuron degeneration without aggregation in "FUSDelta14” knockin mice. Brain 140, 2797-2805 (2017).

135. Marinkovic, P. et al. Axonal transport deficits and degeneration can evolveindependently in mouse models of amyotrophic lateral sclerosis. Proc. Natl Acad. Sci. USA 109, 42964301 (2012).

136. Malik, B. et al. Absence of disturbed axonal transport in spinal and bulbar muscular atrophy. Hum. Mol. Genet. 20, 1776-1786 (2011).

137. Sorbara, C. D. et al. Pervasive axonal transport deficits in multiple sclerosis models. Neuron 84, 1183-1190 (2014).

138. Morfini, G. et al. JNK mediates pathogenic effects of polyglutamine-expanded androgen receptor on fast axonal transport. Nat. Neurosci. 9, 907-916 (2006).

139. Halievski, K., Kemp, M. Q., Breedlove, S. M., Miller, K. E. \& Jordan, C. L. Non-cellautonomous regulation of retrograde motoneuronal axonal transport in an SBMA mouse model. eNeuro 3, e0062-16.2016 (2016).

140. Wang, W. et al. The ALS disease-associated mutant TDP-43 impairs mitochondrial dynamics and function in motor neurons. Hum. Mol. Genet. 22, 4706-4719 (2013).

141. Morfini, G. A. et al. Inhibition of fast axonal transport by pathogenic SOD1 involves activation of p38 MAP kinase. PLOS ONE 8, e65235 (2013).

142. Moller, A., Bauer, C. S., Cohen, R. N., Webster, C. P. \& De Vos, K. J. Amyotrophic lateral sclerosis-associated mutant SOD1 inhibits anterograde axonal transport of mitochondria by reducing Miro1 levels. Hum. Mol. Genet. 26, 4668-4679 (2017).

143. Gibbs, K. L. et al. Inhibiting p38 MAPK alpha rescues axonal retrograde transport 
defects in a mouse model of ALS. Cell Death Dis. 9, 596 (2018).

144. Ruschel, J. et al. Systemic administration of epothilone B promotes axon regeneration after spinal cord injury. Science 348, 347-352 (2015).

145. Mar, F. M., Bonni, A. \& Sousa, M. M. Cell intrinsic control of axon regeneration. EMBO Rep. 15, 254-263 (2014).

146. Clark, A.J. et al. Epothilone D accelerates disease progression in the SOD1 ${ }^{\mathrm{G} 93 \mathrm{~A}}$ mouse model of amyotrophic lateral sclerosis. Neuropathol. Appl. Neurobiol. 44, 590-605 (2018).

147. Reed, N. A. et al. Microtubule acetylation promotes kinesin-1 binding and transport. Curr. Biol. 16, 2166-2172 (2006).

148. Dompierre, J. P. et al. Histone deacetylase 6 inhibition compensates for the transport deficit in Huntington's disease by increasing tubulin acetylation. J. Neurosci. 27, 35713583 (2007).

149. d'Ydewalle, C. et al. HDAC6 inhibitors reverse axonal loss in a mouse model of mutant HSPB1-induced Charcot-Marie-Tooth disease. Nat. Med. 17, 968-974 (2011).

150. Mo, Z. et al. Aberrant GlyRS-HDAC6 interaction linked to axonal transport deficits in Charcot-Marie-Tooth neuropathy. Nat. Commun. 9, 1007 (2018).

151. Taes, I. et al. Hdac6 deletion delays disease progression in the SOD $1^{\mathrm{G} 93 \mathrm{~A}}$ mouse model of ALS. Hum. Mol. Genet. 22, 1783-1790 (2013).

152. Kalinski, A. L. et al. Deacetylation of Miro1 by HDAC6 blocks mitochondrial transport and mediates axon growth inhibition. J. Cell Biol. 218, 1871-1890 (2019).

153. Zhang, K. et al. Defective axonal transport of Rab7 GTPase results in dysregulated trophic signaling. J. Neurosci. 33, 7451-7462 (2013).

154. Cioni, J.-M. et al. Late endosomes act as mRNA translation platforms and sustain mitochondria in axons. Cell 176, 56-72 (2019). 
155. Zhu, Y. B. \& Sheng, Z. H. Increased axonal mitochondrial mobility does not slow amyotrophic lateral sclerosis (ALS)-like disease in mutant SOD1 mice. J. Biol. Chem. 286, 23432-23440 (2011).

156. Perlson, E. et al. A switch in retrograde signaling from survival to stress in rapid-onset neurodegeneration. J. Neurosci. 29, 9903-9917 (2009).

157. Fu, M. \& Holzbaur, E. L. F. JIP1 regulates the directionality of APP axonal transport by coordinating kinesin and dynein motors. J. Cell Biol. 202, 495-508 (2013).

158. Lee, S., Pant, H. C. \& Shea, T. B. Divergent and convergent roles for kinases and phosphatases in neurofilament dynamics. J. Cell Sci. 127, 4064-4077 (2014).

159. Stevenson, A. et al. Riluzole protects against glutamate-induced slowing of neurofilament axonal transport. Neurosci. Lett. 454, 161-164 (2009).

160. Tortarolo, M. et al. Persistent activation of $\mathrm{p} 38$ mitogen-activated protein kinase in a mouse model of familial amyotrophic lateral sclerosis correlates with disease progression. Mol. Cell. Neurosci. 23, 180-192 (2003).

161. Ackerley, S. et al. p38a stress-activated protein kinase phosphorylates neurofilaments and is associated with neurofilament pathology in amyotrophic lateral sclerosis. Mol. Cell. Neurosci. 26, 354-364 (2004).

162. Dewil, M., dela Cruz, V. F., van den Bosch, L. \& Robberecht, W. Inhibition of p38 mitogen activated protein kinase activation and mutant SOD1 ${ }^{\mathrm{G} 93 \mathrm{~A}}$-induced motor neuron death. Neurobiol. Dis. 26, 332-341 (2007).

163. Chico, L. K., Van Eldik, L. J. \& Watterson, D. M. Targeting protein kinases in central nervous system disorders. Nat. Rev. Drug Discov. 8, 892-909 (2009).

164. Hetman, M. \& Gozdz, A. Role of extracellular signal regulated kinases 1 and 2 in neuronal survival. Eur. J. Biochem. 271, 2050-2055 (2004).

165. Hur, E.-M. \& Zhou, F.-Q. GSK3 signalling in neural development. Nat. Rev. Neurosci. 
11, 539-551 (2010).

166. Coffey, E. T. Nuclear and cytosolic JNK signalling in neurons. Nat. Rev. Neurosci. 15, 285-299 (2014).

167. Ally, S., Larson, A. G., Barlan, K., Rice, S. E. \& Gelfand, V. I. Opposite-polarity motors activate one another to trigger cargo transport in live cells. J. Cell Biol. 187, 1071-1082 (2009).

168. Schuster, M. et al. Kinesin-3 and dynein cooperate in long-range retrograde endosome motility along a nonuniform microtubule array. Mol. Biol. Cell 22, 3645-3657 (2011).

169. Wu, C., Watts, M. E. \& Rubin, L. L. MAP4K4 activation mediates motor neuron degeneration in amyotrophic lateral sclerosis. Cell Rep. 26, 1143-1156 (2019).

170. Xie, Y. et al. Endolysosomal deficits augment mitochondria pathology in spinal motor neurons of asymptomatic fALS mice. Neuron 87, 355-370 (2015).

\section{Acknowledgements}

The authors' work is supported by the Medical Research Council Career Development Award (MR/S006990/1 to J.N.S), a Wellcome Trust Postdoctoral Fellowship for Clinicians (110043/Z/15/Z to A.M.R.), a Wellcome Trust Senior Investigator Award (107116/Z/15/Z to G.S), the European Union's Horizon 2020 Research and Innovation programme under grant agreement 739572 (G.S.) and a UK Dementia Research Institute Foundation award (G.S.).

\section{Author contributions}

All authors contributed to the researching, writing and editing of this Review.

\section{Competing interests}

The authors declare no competing interests. 


\section{Peer review information}

Nature Reviews Neurology thanks K. De Vos and other anonymous reviewer(s) for their contribution to the peer review of this work.

\section{Publisher's note}

Springer Nature remains neutral with regard to jurisdictional claims in published maps and institutional affiliations.

\section{Databases}

Online Mendelian Inheritance in Man: http://www.omim.org/

\section{Key points}

- Mutations in various genes encoding components of the axonal transport machinery have been implicated in the pathogenesis of neurological diseases.

- Defective axonal trafficking has been linked to many nervous system disorders, but whether it is a cause or consequence of neuropathology remains largely unresolved.

- Intravital imaging of transport in axons of live mice provides some of the most compelling evidence that trafficking disturbances contribute to neuronal dysfunction.

- Targeting of specific mechanisms of axonal transport might be a valid therapeutic strategy to treat neurological disease. 


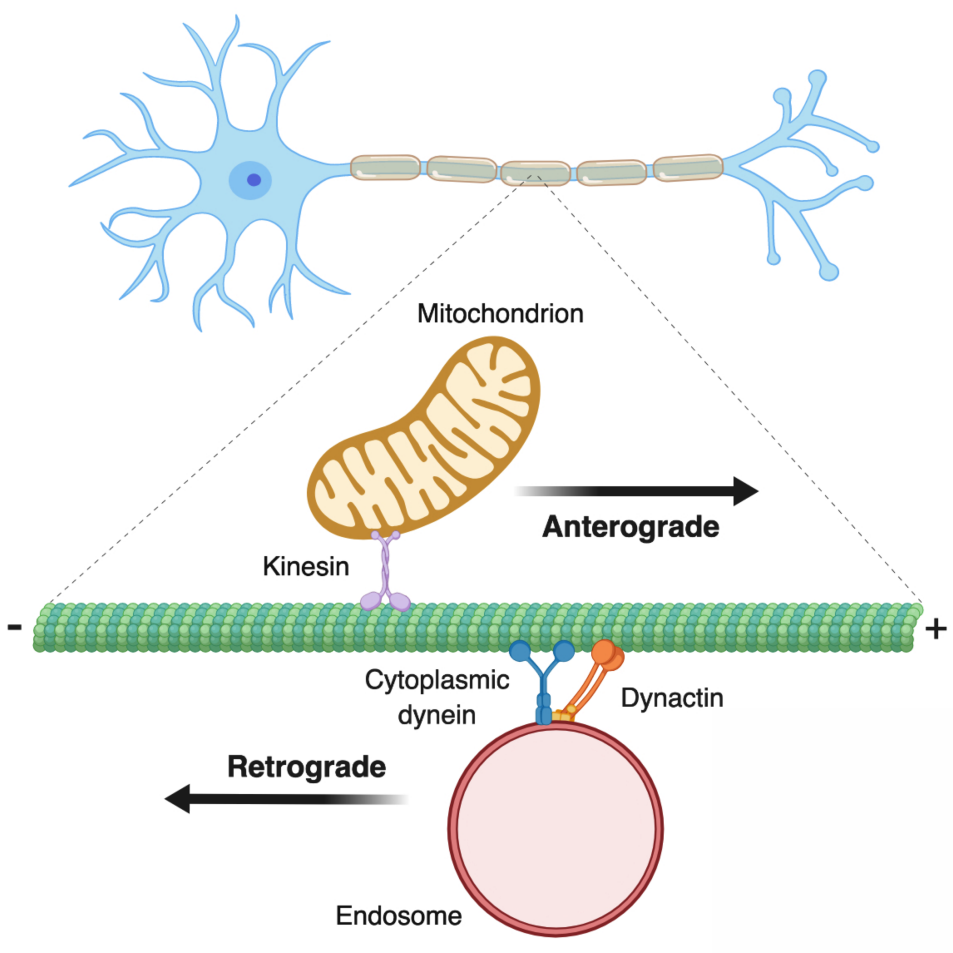

\section{Neurological Disease-linked \\ Genes}

KIF5A, KIF5C, KIF1A, KIF1C, KIF14, KIF16A, KIF4A, KIF7, KIF21A, KIF11, KIF10, KIF6, KIF15, KIF2A, KBP

Anterograde Transport Machinery

TUBA1A, TUBA8, TUBB, TUBB2A, TUBB2B, TUBB3, TUBB4A, TUBB4B, TUBB6, TUBG1

Microtubule Network

DYNC1H1, DCTN1, BICD2, LIS1, NDE1

Retrograde Transport Machinery

Figure 1 The axonal transport machinery. Mutations in genes that are integral to the anterograde and retrograde axonal transport machineries, as well as to the microtubule network, have been causally linked to many nervous system diseases (Table 1). Note that motor proteins can attach to and traffic many different cargoes and are not restricted to those depicted; for example, kinesin can transport vesicles and dynein can transport mitochondria. The components of the machinery are not shown to scale. 
Table 1 | Axonal transport gene mutations and neurological disease.

\begin{tabular}{|c|c|c|c|c|c|}
\hline $\begin{array}{l}\begin{array}{l}\text { Protein } \\
\text { complex }\end{array} \\
\end{array}$ & Gene & Inheritance & Disease & $\begin{array}{l}\text { OMIM } \\
\text { entry }\end{array}$ & Phenotype \\
\hline \multicolumn{6}{|c|}{ Anterograde transport machinery } \\
\hline Kinesin-1 & KIF5A & $\begin{array}{l}\mathrm{AD} \\
\mathrm{AD}\end{array}$ & $\begin{array}{l}\text { Spastic paraplegia } 10 \\
\text { (SPG10)/Charcot-Marie-- } \\
\text { Tooth disease type } 2 \\
\text { (CMT2) } \\
\text { Neonatal intractable } \\
\text { myoclonus (NEIMY) } \\
\text { Amyotrophic lateral } \\
\text { sclerosis (ALS) }\end{array}$ & $\begin{array}{l}604187 \\
617235 \\
617921\end{array}$ & $\begin{array}{l}\text { Neurodegenerative } \\
\text { Neurodevelopmental } \\
\text { Neurodegenerative }\end{array}$ \\
\hline Kinesin-1 & KIF5C & $\mathrm{AD}$ & $\begin{array}{l}\text { Complex cortical dysplasia } \\
\text { with other brain } \\
\text { malformations } 2 \\
(\mathrm{CDCBM} 2) \\
\end{array}$ & 615282 & Neurodevelopmental \\
\hline Kinesin-3 & KIFIA & $\begin{array}{l}\mathrm{AR} \\
\mathrm{AR}\end{array}$ & $\begin{array}{l}\text { Mental retardation, } \\
\text { autosomal dominant } 9 \\
\text { (MRD9) } \\
\text { Hereditary sensory } \\
\text { neuropathy type IIC } \\
\text { (HSN2C) } \\
\text { Spastic paraplegia } 30 \\
\text { (SPG30) }\end{array}$ & $\begin{array}{l}614213 \\
610357\end{array}$ & $\begin{array}{l}\text { Neurodevelopmental } \\
\text { Neurodegenerative } \\
\text { Neurodegenerative }\end{array}$ \\
\hline Kinesin-3 & KIFIC & AR & $\begin{array}{l}\text { Spastic ataxia } 2 \\
\text { (SPAX2)/spastic } \\
\text { paraplegia } 58(\text { SPG58) }\end{array}$ & 611302 & Neurodegenerative \\
\hline Kinesin-3 & KIF14 & $\begin{array}{l}\mathrm{AR} \\
\mathrm{AR}\end{array}$ & $\begin{array}{l}\text { Meckel syndrome } 12 \\
\text { (MKS12) } \\
\text { Primary microcephaly } 20 \\
(\mathrm{MCPH} 20)\end{array}$ & $\begin{array}{l}616258 \\
617914\end{array}$ & $\begin{array}{l}\text { Neurodevelopmental } \\
\text { Neurodevelopmental }\end{array}$ \\
\hline Kinesin-3 & KIF16A & AR & $\begin{array}{l}\text { Microcephaly and } \\
\text { blindness (single case) }\end{array}$ & NA & Neurodevelopmental \\
\hline Kinesin-4 & KIF4A & $\mathrm{XL}$ & $\begin{array}{l}\text { Mental retardation } \\
\text { (MRX100; single case) }\end{array}$ & 300923 & Neurodevelopmental \\
\hline Kinesin-4 & KIF7* & AR & $\begin{array}{l}\text { Acrocallosal syndrome } \\
\text { (ACLS)/Joubert syndrome } \\
12 \text { (JBTS12) }\end{array}$ & 200990 & Neurodevelopmental \\
\hline Kinesin-4 & KIF21A & $\mathrm{AD}$ & $\begin{array}{l}\text { Congenital fibrosis of } \\
\text { extraocular muscles 1/3B } \\
\text { (CFEOM1/3B) }\end{array}$ & 135700 & Neurodevelopmental \\
\hline Kinesin-5 & KIF11 & $\mathrm{AD}$ & $\begin{array}{l}\text { Microcephaly with or } \\
\text { without chorioretinopathy, } \\
\text { lymphedema, or mental } \\
\text { retardation (MCLMR) }\end{array}$ & 152950 & Neurodevelopmental \\
\hline Kinesin-7 & KIF10* & AR & $\begin{array}{l}\text { Primary microcephaly } 13 \\
(\mathrm{MCPH} 13)\end{array}$ & 616051 & Neurodevelopmental \\
\hline Kinesin-9 & KIF6* & AR & $\begin{array}{l}\text { Intellectual disability } \\
\text { (single case) }\end{array}$ & NA & Neurodevelopmental \\
\hline Kinesin-12 & KIF15 & AR & $\begin{array}{l}\text { Microcephaly and } \\
\text { thrombocytopenia (single } \\
\text { case) }\end{array}$ & NA & Neurodevelopmental \\
\hline Kinesin-13 & $K I F 2 A^{*}$ & $\mathrm{AD}$ & $\begin{array}{l}\text { Cortical dysplasia, } \\
\text { complex, with other brain } \\
\text { malformations } 3 \\
\text { (CDCBM3) }\end{array}$ & 615411 & Neurodevelopmental \\
\hline $\begin{array}{l}\text { Kinesin- } \\
\text { binding protein }\end{array}$ & $\begin{array}{l}\text { KIF1BP/ } \\
\text { KBP } \\
\end{array}$ & AR & $\begin{array}{l}\text { Goldberg-Shprintzen } \\
\text { syndrome (GOSHS) }\end{array}$ & 609460 & iental \\
\hline
\end{tabular}




\begin{tabular}{|c|c|c|c|c|c|}
\hline \multicolumn{6}{|c|}{ Retrograde transport machinery } \\
\hline $\begin{array}{l}\text { Dynein } \\
\text { cytoplasmic } 1 \\
\text { heavy chain } 1\end{array}$ & $D Y N C l H 1$ & $\mathrm{AD}$ & $\begin{array}{l}\text { Mental retardation } 13 \\
\text { (MRD13) } \\
\text { Lower extremity- } \\
\text { predominant spinal } \\
\text { muscular atrophy-1 } \\
\text { (SMALED1) }\end{array}$ & $\begin{array}{l}614563 \\
18600\end{array}$ & $\begin{array}{l}\text { Neurodevelopmental } \\
\text { Neurodevelopmental }\end{array}$ \\
\hline $\begin{array}{l}\text { Dynactin } \\
1 / \mathrm{P} 150^{\text {Glued }}\end{array}$ & DCTN1 & $\mathrm{AD}$ & $\begin{array}{l}\text { Distal hereditary motor } \\
\text { neuropathy type VIIB } \\
\text { (HMN7B) } \\
\text { Perry syndrome }\end{array}$ & $\begin{array}{l}607641 \\
168605\end{array}$ & $\begin{array}{l}\text { Neurodegenerative } \\
\text { Neurodegenerative }\end{array}$ \\
\hline Bicaudal D2 & $B I C D 2$ & $\mathrm{AD}$ & $\begin{array}{l}\text { Spinal muscular atrophy, } \\
\text { lower extremity- } \\
\text { predominant, 2A } \\
\text { (SMALED2A) }\end{array}$ & 615290 & Neurodevelopmental \\
\hline $\begin{array}{l}\text { Lissencephaly } \\
1\end{array}$ & \begin{tabular}{|l|} 
LIS1/ \\
PAFAH1B1
\end{tabular} & $\mathrm{AD}$ & $\begin{array}{l}\text { Lissencephaly, subcortical } \\
\text { laminar heterotropia }\end{array}$ & 601545 & Neurodevelopmental \\
\hline $\begin{array}{l}\text { NudE neuro- } \\
\text { development } \\
\text { protein } 1\end{array}$ & NDE1 & $\mathrm{AR}$ & $\begin{array}{l}\text { Microhydranencephaly } \\
\text { (MHAC) } \\
\text { Lissencephaly } 4 \text { (LIS4) } \\
\text { with microcephaly } \\
\end{array}$ & $\begin{array}{l}605013 \\
614019\end{array}$ & Neurodevelopmental \\
\hline \multicolumn{6}{|c|}{ Microtubule network } \\
\hline$\alpha 1 \mathrm{~A}-$ Tubulin & TUBA1A & $\mathrm{AD}$ & Lissencephaly 3 (LIS3) & 611603 & Neurodevelopmental \\
\hline$\alpha 8$-Tubulin & TUBA & $\mathrm{AD}$ & $\begin{array}{l}\text { Complex cortical dysplasia } \\
\text { with other brain } \\
\text { malformations } 8 \\
\text { (CDCBM8) }\end{array}$ & 613180 & Neurodevelopmental \\
\hline $\begin{array}{l}\text { B-Tubulin } \\
\text { class } 1\end{array}$ & $T U B B$ & $\mathrm{AD}$ & $\begin{array}{l}\text { Complex cortical dysplasia } \\
\text { with other brain } \\
\text { malformations } 6 \\
\text { (CDCBM6) }\end{array}$ & 615771 & Neurodevelopmental \\
\hline $\begin{array}{l}\beta 2 \mathrm{~A}-T u b u l i n \\
\text { class IIa }\end{array}$ & $T U B B 2 A$ & $\mathrm{AD}$ & $\begin{array}{l}\text { Complex cortical dysplasia } \\
\text { with other brain } \\
\text { malformations } 5 \\
\text { (CDCBM5) }\end{array}$ & 615763 & Neurodevelopmental \\
\hline $\begin{array}{l}\beta 2 \mathrm{~A}-T u b u l i n \\
\text { class IIb }\end{array}$ & $T U B B 2 B$ & $\mathrm{AD}$ & $\begin{array}{l}\text { Complex cortical dysplasia } \\
\text { with other brain } \\
\text { malformations } 7 \\
(\text { CDCBM7) }\end{array}$ & 610031 & Neurodevelopmental \\
\hline $\begin{array}{l}\beta 3 \text {-Tubulin } \\
\text { class III }\end{array}$ & TUBB3 & $\begin{array}{l}\mathrm{AD} \\
\mathrm{AD}\end{array}$ & $\begin{array}{l}\text { Complex cortical dysplasia } \\
\text { with other brain } \\
\text { malformations } 1 \\
\text { (CDCBM1) } \\
\text { Congenital fibrosis of } \\
\text { extraocular muscles 3A } \\
\text { (CFEOM3A) }\end{array}$ & $\begin{array}{l}614039 \\
600638\end{array}$ & $\begin{array}{l}\text { Neurodevelopmental } \\
\text { Neurodevelopmental }\end{array}$ \\
\hline $\begin{array}{l}\beta 4 \mathrm{~B}-\text { Tubulin } \\
\text { class IVa }\end{array}$ & $T U B B 4 A$ & $\begin{array}{l}\mathrm{AD} \\
\mathrm{AD}\end{array}$ & $\begin{array}{l}\text { Torsion dystonia } 4 \\
\text { (DYT4) } \\
\text { Hypomyelinating } \\
\text { leukodystrophy } 6 \text { (HLD6) }\end{array}$ & $\begin{array}{l}612438 \\
617879\end{array}$ & $\begin{array}{l}\text { Neurodegenerative } \\
\text { Neurodegenerative }\end{array}$ \\
\hline $\begin{array}{l}\beta 4 \mathrm{~B}-\mathrm{Tubulin} \\
\text { class IVb }\end{array}$ & $T U B B 4 B$ & $\mathrm{AD}$ & $\begin{array}{l}\text { Leber congenital } \\
\text { amaurosis with early-onset } \\
\text { deafness (LCAEOD) }\end{array}$ & 617879 & Neurodegenerative \\
\hline $\begin{array}{l}\beta 6-T u b u l i n \\
\text { class V }\end{array}$ & TUBB6 & $\mathrm{AD}$ & $\begin{array}{l}\text { Congenital facial palsy } \\
\text { with ptosis and } \\
\text { velopharyngeal } \\
\text { dysfunction (FPVEPD) }\end{array}$ & 617732 & Neurodevelopmental \\
\hline
\end{tabular}




\begin{tabular}{|l|l|l|l|l|l|}
\hline$\gamma 1-$ Tubulin & TUBG1 & AD & $\begin{array}{l}\text { Complex cortical dysplasia } \\
\text { with other brain } \\
\text { malformations 4 } \\
\text { (CDCBM4) } \\
\text { Hypoparathyroidism- } \\
\text { retardation-dysmorphism } \\
\text { syndrome (HRDS) }\end{array}$ & 241410 & Neurodevelopmental \\
\hline
\end{tabular}

The table lists genes encoding components of the anterograde and retrograde transport complexes and microtubule network that have been implicated in neurological disease, along with their associated mode of inheritance and the nature of the phenotype (neurodevelopmental or neurodegenerative). *Mutated transport protein is implicated in non-motile cilia as opposed to intracellular transport. $\mathrm{AD}$, autosomal dominant; $\mathrm{AR}$, autosomal recessive; NA, not applicable; OMIM, Online Mendelian Inheritance in Man; XL, X-linked.

\section{Glossary}

\section{Processivity}

The ability of motors/cargoes to undergo axonal transport without dissociation from microtubules.

\section{Coiled-coil domains}

A structural motif comprised of two or more alpha-helices wrapped around each other to form a supercoil. The coiled-coil domain of the cytoplasmic dynein-dynactin complex connects the ATPase domain with the microtubule-binding domain.

\section{Run length}

The total displacement covered by a motor/cargo without pausing.

\section{Microtubule gliding assays}


An experimental technique used to assess the activity of motor proteins, in which microtubules and ATP are applied to motors bound to glass coverslips.

\section{N-ethyl-N-nitrosourea (ENU)}

A mutagen used to generate transgenic mouse models.

\section{Endosomes}

Membranous organelles involved in intracellular transport, sorting and delivery of a variety of substances, including growth factors, internalised from the cell exterior. 